\section{Practice Based Research in the Context of Spatial Transformation A South African Perspective}

Yashaen Luckan

University of Kwa-Zulu Natal

Nischolan Pillay

University of Johannesburg

\section{ABSTRACT}

The spatial inequities of apartheid severely compromised the advancement of historically marginalised societies in South Africa. Exclusive barriers to access and opportunity defined an underlying geo-social intent for the oppression of societies, hereafter referred to as historically disadvantaged communities. The socio-economic injustices extended beyond physical spatial barriers into the realm of intellectual imprisonment effected by pedagogic exclusion. This ultimately prevented knowledge generation by exclusion of lived experiences in historically disadvantaged communities. The research approach is informed by a problem which focuses on pedagogic exclusion and the critical role of inclusive pedagogies and participatory approaches to research in architectural education for the advancement of society in order to promote spatial transformation.

\section{PROBLEM STATEMENT}

The post-apartheid South African agenda realised a range of policies, frameworks and strategies that focus on redress and transformation to benefit the vast majority of the population who were disenfranchised by a socially unjust previous regime. While much focus has been on economic reform and social infrastructure, the critical position of architecture as an enabler of socio-economic redress through spatial transformation has not been adequately interrogated. Furthermore, the prevalent approaches to research and knowledge generation confined to institutions of higher learning implicitly disregard the value of practice-based research. This extends to the exclusion of practice-based knowledge generation in the historically disadvantaged communities; a serious compromise to real spatial transformation. The status quo is that these communities continue to be served by professionals who have never lived the socio-economic challenges facing these communities. The pedagogic exclusion of historically disadvantaged communities expresses the intention of intellectual oppression characteristic of apartheid, which severely compromises the socio-economic advancement of historically marginalised societies - barriers to the advancement of knowledge and practice continues to spatially compromise historically disadvantaged communities in South Africa. The paper argues for critically responsive architectural practice, based on pedagogic inclusivity, for socio-economic reform through spatial transformation consequent to a process of practice-engaged, contextually situated research and knowledge transfer. This, however, cannot be achieved without changes of attitudes in the education and training of architects; traditional approaches to curriculum and pedagogy require critical reform in order to define the sources of knowledge production and critical practice within the 21st century.

\section{AIM}

The aim of this research paper is to define the principles and approaches to architectural research in order to promote the socio-economic redress \& spatial transformation of historically disadvantaged communities in South Africa. 


\section{METHODOLOGY}

The research strategy is based on a qualitative approach in the interpretation of data collected from primary and secondary sources. Primary data is sourced from auto-ethnographic inquiry due to the authors' own experiences as practicing architects and academics, who lived through the geographic and socio-economic segregation effected by apartheid legislation. Secondary data analysis is in the form of a literature review of critical discourses on the role of education and practice for the advancement of an inclusive knowledge society for socio-economic redress and spatial transformation.

\section{DISCUSSION}

\section{ACRITIQUEOFTHEHISTORICALMETHODSOF ARCHITECTURALEDUCATION}

Built environment curricula, especially those in architecture, continue to progress along the controls of canon and hegemony while attempting to respond to the transformation agendas of post-apartheid South Africa. Design teaching continues to develop within the silos of academia; the architectural studio continues to exist as an introverted pod withdrawn from the nuances of society. The current system has a strong resemblance with the mid-18th century academies which were established during the Renaissance period in Europe.

This socially disconnected teaching practice was epitomised by the pedagogic approaches of the ateliers of the Ecole des Beaux-Arts in France ${ }^{1}$ whereby the close relation of architectural practice to the culture of making was lost.

The problem of dislocated education and training is compounded by pedagogic approaches that exclude the potentiality of lived experiences in complex social contexts. While more projects are situated in the historically marginalised communities, the pedagogic approaches are still rather exclusive. It is therefore necessary to briefly review some of the contemporary approaches to teaching and learning in order to understand the attitudes and entrenched practices which hinder the potential value of architectural education as an enabler of spatial transformation.

\section{BEHAVIOURS, TRADITIONS AND ATTITUDES THAT INHIBIT SOCIALLY RESPONSIVE PRACTICE}

A critique of the prevalent system of architectural education in South Africa requires an informed understanding of the broader approaches to curriculum and pedagogy that define contemporary higher education. Reference is made to Schubert ${ }^{2}$ who elaborated on the concept of the hidden curriculum whereby the social relationships between participants in learning, students, teachers and members of society alike, construct and refine the character of students. His four perspectives on curriculum aligned to character types, namely, social behaviourist, intellectual traditionalist, experientialist and critical reconstructionist provide a valuable framework for a critique of prevalent architectural teaching practice.

Architectural education in South Africa continues to express qualities of social behaviourist and intellectual traditionalist approaches which can be correlated to the Beaux-Arts system which epitomised the architectural studio as a confined and controlled creative silo, disconnected from society. While external images of social success and the behavioural observation thereof would form the basis of the behaviourist approach, intellectual traditionalism, while not specific to behavioural observation, would be defined by reliance on the great intellectual works located within the logic of disciplines, inclining the learner towards ideas and philosophies that transcend historic eras, geographic locality, culture, race, gender, and class among others. These two perspectives underpinned the evolution of education over centuries and clearly define the most dominant discourses and approaches of architectural education in South Africa today.

The dominant mode of architectural education is, therefore, one that does not factor in other forms of learning nor does it adequately recognise alternate learning pathways. Practice based research is therefore impeded; knowledge is deemed to be locked in the domain of the formal learning spaces. This paper argues that the value of knowledge acquired through practice experience - practice-based research - is a critical component of learning that cannot be ignored if architecture is to respond to the spatial transformation agenda of post-apartheid South Africa.

\section{EXPERIENTIAL LEARNING AS CATALYST FOR SOCIAL REFORM THROUGH INCLUSIVE PRACTICE}

The Experientialist approach poses an interesting and vitally valid challenge to the two preceding approaches by highlighting the importance of the broader learning context inclusive of practice experience. Another important component to knowledge generation for spatial transformation is the critical value of lived experience of those persons facing the socio-economic challenges in historically disadvantaged communities. This approach embraces diversity and multiculturalism by placing high value on contextually situated problems, practice and shared experiences.

Educational philosopher, John Dewey, promulgated an engaged learning paradigm founded on real life experiences and consequently criticised schooling for being exaggerated rather than supplementary to the ordinary course of living. ${ }^{3}$ The paper further elaborates on the democratisation of knowledge creation by referring to Dewey's ${ }^{4}$ assertion that democratic forms of social life improve access and participation, thereby advancing the quality of human experience. The democratisation of knowledge generation through inclusive pedagogic approaches is vital to any transformative agenda.

Most students at universities, however, find no place for the expression of their own lived experience in the process of architecture and therefore rely on the curriculum and pedagogic approaches of their schools to define their future practice attitudes and attributes; they are vulnerable to exaggerated forms of schooling within the silos of academia. These exaggerated forms of schooling proliferate within a formal system of education that highly values academic research and publication while ignoring the value of practice-based knowledge generation. Lecturers of architectural curricula are recruited based on academic publication and teaching experience, without any acknowledgement of the value of practice generated knowledge; the 
implicit process of research in practice continues remains inconspicuous in the realm of academic research. To emphasise the severity of such system, it is worthy to note that certain institutions do not permit academic staff to engage in practice.

While the intellectual traditionalist approach continues to dominate architectural education the value of practice as a stimulator of incidental learning 5 requires attention as this could effect a socially conscious curriculum for spatial transformation. This interpretation of incidental learning is fundament on the premise that knowledge acquired through practice is an inevitable consequence of conscious and sub-conscious interactions through moments of psycho-spatial encounters in diverse and complex contexts. Any system, therefore, that prevents this type of knowledge generation is in contradiction with the humanistic agenda of spatial transformation.

This paper argues that academics should be supported to engage with the practice of architecture in order to stimulate critical knowledge transfer to society. It is further argued that, with respect to research output, academics in professional practice will enhance knowledge generation through praxis-led research. Architectural education / research therefore requires a critical review in response to the complex socio-economic contexts of historically disadvantaged communities, requiring a redefinition of its modes of knowledge production.

\section{MODES OF KNOWLEDGE PRODUCTION - PROTECTION OR DISRUPTION OF DOMAINS?}

Gibbons et $a^{6}$ defined two modes of knowledge production, widely referenced in higher education, which either promote exclusive or inclusive practice. The paper takes a critical stance against the dominant discipline-specific Mode 1 type of knowledge - exclusive practice that hinges around scientific methodology, norms and quantified judgement of good practice; a controlled disciplinary specific mode confined within institutions of learning and research. Bussey ${ }^{7}$ refers to this dislocation of education, from social contexts to centralised control, to the 18th century rise in institutional modernity whereby modern education served to globalise modernity. He further criticises the discipline-specific approaches of 19th century schooling, stating that modern education failed to prepare students for a future that asks different questions of humanity - a paradox of modern education. ${ }^{7}$ This mode thrives on predetermination, intellectual tradition and canon, which have relevance in many industry focused disciplines and professions. Luckan ${ }^{5}$ refers to this as an industrial pedagogic approach which excludes lived experiences, negating a humanistic agenda which is necessary for spatial transformation.

Architecture, however, cannot avoid engagement with complex and diverse spatial contexts and cannot therefore be adequately served by the prevalent mode 1 approach to knowledge generation. Complexity of context defined by indetermination and multiculturalism requires a complimentary mode which engages with difference and contention. Mode $2^{6}$ provides a relevant alternative; a responsive approach that accommodates trans-disciplinary practice, heterogeneity and transience; it extends beyond the boundaries of institutions and draws into the learning community, a wider range of participants. Mode 2 recognises the value of practitioners as vital to critical pedagogic practice which is rooted in context and interdisciplinary collaboration which underpins a paradigm of practice-led teaching and research, knowledge transfer. Within this paradigm knowledge production may be considered dialogical through synergies with society, whereby knowledge transfer and knowledge generation are interdependent processes between the intellectual domain and socially rooted experience. Mode 2 corelates appropriately with the concept of incidental learning by integrating conscious learning with subconscious learning. It is asserted that the domain of practice / practice-based research promotes a deeper level of critical inquiry. The domain of practice catapults the intellect into a realm of vulnerability and indetermination, primarily due to the frequency of incidental moments in vastly different socio-economic contexts. In essence, practice moves one out of the cognitive comfort zones of the institution / studio into the realities of the societal coalface. The domain of practice is naturally disruptive to entrenched attitudes and process consequent to formal learning; it is essentially a paradigm of lifelong learning founded on inquiry in the process of architectural practice.

\section{DISRUPTION AS VITAL TO RESPONSIVE PRAC-TICE FOR SPATIAL TRANSFORMATION WITHIN THE 21ST CENTURY}

Disruption in the context of this paper refers to the pressures of societal realities, through practice experience, that exposes the inadequacies of a pedagogically exclusive paradigm of learning - formal learning informed by predefined curricula within the silos of institutions of higher learning. It is argued that innovation may be severely inhibited by introvert thinking processes; the inclusion of multiple experiences and multiple intelligences ${ }^{8}$ is required to spark innovation. Johansson ${ }^{9}$ defines disruption as a clash of ideas necessary to spark innovation. This paper argues that inclusive pedagogic approaches will lead to such clash of ideas which are necessary and vital to responsive architectural practice in the endeavour to effect spatial transformation.

The complexity of societal realities naturally disrupts the exclusive processes of formal cognitive engagement thereby advancing inquiry into the realm of engagement, participation and collaboration; it brings into play the left brain / extrovert faculties of the mind. This paper therefore affirms that disruption affords various possibilities for practice-based knowledge generation and that the knowledge community is similarly open to a much broader range of participants, including the lived experiences of persons resident in historically disadvantaged communities. The advances in technology beyond the digital age, now in the era of the fourth industrial revolution, turns traditional education practice on its head; knowledge generation has consequently broken out of the confines of institutional barriers. The domain of practice is in an opportune space to advance scholarship through 
praxis-led research in order to effect spatial transformation. What are the possibilities offered within this 21st century paradigm?

\section{TOWARDS A PEDAGOGICALLY INCLUSIVE PARADIGM OF ARCHITECTURAL EDUCATION IN SOUTH AFRICA}

The South African architectural profession has quite a unique demographic expression due to various reasons. During the apartheid era, a bifurcated post-secondary education system categorised education into two separate streams. The first was university education, which served to educate and train highly qualified professionals. The second was a system of technical education for the labour force, the majority of whom did not have the privilege of higher education due to political, social and economic circumstances. These persons worked in practices / industries headed by highly qualified professionals. Nowadays a significant number of these technically skilled persons run practices, serving their own historically disadvantaged communities. While qualified architects also face pedagogic exclusion, albeit at a different level, focus is on those lesser qualified persons who render architectural services to their communities in historically disadvantaged areas. The main challenge facing these lower qualified professionals is the lack of professional advancement due to barriers to higher education, which severely compromises spatial transformation.

Post-apartheid educational reform focused on the plight of the historically disadvantaged communities, however to date, the reality of the current system is that it does not address the needs of that very group of persons who could not access high quality education during the apartheid regime. These persons continue to face barriers to access nowadays due to pedagogic exclusion - neither the curriculum nor the pedagogic approaches relate to their socio-economic and spatial contexts. Their wealth of lived experiences in real socio-economically challenging contexts is disregarded by a pedagogically exclusive system resulting in a perpetuation of lesser quality architectural services in the historically disadvantaged communities. Similarly, their practice experience is excluded from the prevalent definition of research. Given this situation and the fact that the practical implementation of transformative initiatives at universities do not respond to their requirements, what opportunities do the 21st century paradigm afford this group of persons in mid to late career advancement? The 4 th industrial revolution ${ }^{10}$ has brought about an unprecedented disruption which is critical to professional education and training. Its principles question the very core assumptions, attitudes and practices of traditional forms of learning. It essentially disrupts social behaviourist and intellectual traditionalist approaches through open science, the free city and open access to courseware; the virtual learning environment dislocates the physical boundaries of institutions thereby reducing the barriers of distance. Distance in this context refers both to pedagogic barriers as well as the physical distances that define the demographic segregation of communities in South Africa.

This paper argues that the "smart city" concept be reinterpreted to, what the author refers to as, the concept of "smart citizenship". It is argued that smart citizenship is about empowerment through an alternate curriculum, inclusive pedagogies and an inclusive paradigm of knowledge generation [research], enabled by the 4th industrial revolution.

This paper asserts that spatial transformation of disadvantaged communities, in the 21st century, is possible as the foundations of research, its methodologies and processes are inevitably reformed by smart citizenship, whereby the lived experiences of people in place become critical factors in knowledge generation. The learning and research community / knowledge society is thereby enriched due to the inclusion of a depth of ethnographic and auto-ethnographic sources of data that is critically lacking in South Africa. It is argued that the multiple experiences and intelligences of people in challenging socio-economic contexts are drivers of research that could contribute to spatial transformation through attitudes and positions of critical reconstruction ${ }^{2}$. Architectural practitioners resident in these communities, given the opportunities to learning in the virtual environment, can build on their skills sets by bridging gaps in knowledge, importantly, the potential for research through practice-based experience can advance critical reconstruction which is necessary for spatial transformation. While reference to the 4 th industrial revolution sparks concerns of technology focused approaches, it is possible that a carefully considered, culturally inclusive approach will promote a humanistic agenda through the advancement of human potentiality within a paradigm of inclusivity that exceeds geo and socio sentiment. The authors argue for a responsive curriculum based on flexibility, adaptability and inclusivity - an agile curriculum for the 21st Century. This paper therefore asserts that the opportunities for collaboration and engagement with the global knowledge society afforded by open access could very well also afford new synergies between practice-based research and the formal research within institutions of higher learning. The effect of a synergistic or agile mode of research through the merger of two currently separated domains can enrich research output and knowledge transfer to communities in need. The paper therefore posits a synergistic, mutually inclusive paradigm of research, which is an area of potential that is yet to be realised in the South African context.

This mutually inclusive paradigm is defined by synergises between the intellectual, experiential and practice-based domains of research; it is mutually inclusive of introvert and extrovert processes, drawing on multiple experiences and intelligences within a much more complex research paradigm. A pedagogically inclusive paradigm of contention and clash emerges, that could spark new ideas, alternate ways of thinking and innovation to unearth a hidden curriculum for spatial transformation through critical reconstruction.

\section{CONCLUSION}

This paper looked at practice-based research with a different lens, defined by the need to respond to the spatial transformation agenda of post-apartheid South Africa. The discussion focused on the challenges of historically disadvantaged communities within a context defined by socio-economic and spatial disparities. The authors themselves lived the experiences of socio-economic challenges and intellectual oppression. Pedagogic exclusion of historically marginalised 
persons was identified as a critical factor that formed a barrier to intellectual emancipation and professional advancement, which compromises spatial transformation in post-apartheid South Africa.

Different approaches and attitudes to professional education and training were reviewed and it was determined that the prevalent modes were pedagogically exclusionary and therefore perpetuated the problem of barriers to societal advancement and spatial transformation. The proposition of the paper was based on inclusive pedagogies and participatory research approaches which implicitly questioned the sources of knowledge and research. A major hindrance to pedagogic access was the traditional attitudes and processes of professional education which remain confined within the silos of higher education institutions.

The paper looked into alternate modes of education and research afforded by the technological advancements of the 21st century, notably, the 4th industrial revolution. The concept of smart citizenship was proposed as a strategy to empower historically disadvantaged communities by way of intellectual emancipation made possible by open science, open access to courseware and the free city concept. The inherent value of community-based architectural practice, situated in socio-economically disadvantaged communities, was emphasised as a key driver for contextually based knowledge generation through widened participation, the inclusion of multiple experiences and multiple intelligences. An inevitable, consequent clash of ideas and contention would spark innovation to effect spatial transformation through experiential learning, practice-based research and critical reconstruction - an inclusive pedagogic paradigm for spatial transformation in post-apartheid South Africa.

\section{Notes}

1. Thomas Howarth, 1959, Background to Architectural Education, Journal of Architectural Education

2. William Henry Schubert, Character Education from Four Perspectives on Curriculum, Teachers College Record

3. John Dewey and Evelyn Dewey, 1915, Schools of To-Morrow, 1st ed, New York: E.P. Dutton \& Company.

4. John Dewey, 1938, Experience and Education, 1st ed, New York: Macmillan Pub. Co.

5. Yashaen Luckan, 2017, The Transformation of Architectural Pedagogy and Learning Space Development: Towards a New Model for Architectural Education at Universities of Technology in South Africa, Ph.D Thesis: University of KwaZulu-Natal, South Africa.

6. Michael Gibbons, Camille Limoges, Helga Nowotny, Simon Schwartzman, Peter Scott and Martin Trow, 1994, The New Production of Knowledge, Edited by Michael Gibbons.

7. Marcus Bussey, 2010, Education for Liberation: A Corner Stone of Prout, In Understanding Prout, Essays on Sustainability and Transformation.

8. Ashraf. M. Salama, 2015, Spatial Design Education: New Directions for Pedagogy in Architecture and Beyond, Surrey:
Ashgate Publishing.

9. Frans Johansson, 2017, The Medici Effect, Boston: Harvard Business School Press.

10. Klaus Schwab, 2016, The Fourth Industrial Revolution, Geneva: World Economic Forum.

\section{Sources}

Bussy, M. 2010. Education for Liberation: A Corner Stone of Prout, In Understanding Prout, Essays on Sustainability and Transformation. 1:1-27.

Dewey, J \& Dewey, E, 1915, Schools of To-Morrow, 1st ed, New York: E.P. Dutton \& Company.

Dewey, J, 1938, Experience and Education, 1st ed, New York: Macmillan Pub. Co.

Gibbons, M., Lemoges, C., Nowotny, H. Schwartsman, S., Scott, P. and Trow, M. 1994. The New Production of Knowledge: The Dynamics of Science and Research in Contemporary Societies. California: SAGE Publications Ltd.

Howarth, T. 1959. Background to Architectural Education. Journal of Architectural Education. 14(2): 25-30.

Johansson, F. 2017. The Medici Effect. Boston: Harvard Business School Press.

Luckan, Y, 2017, The Transformation of Architectural Pedagogy and Learning Space Development: Towards a New Model for Architectural Education at Universities of Technology in South Africa, Ph.D Thesis: University of KwaZulu-Natal, South Africa.

Salama, A.M. 2015. Spatial Design Education: New Directions for Pedagogy in Architecture and Beyond. Surrey: Ashgate Publishing

Schubert, W.H. 1997. Character Education from Four Perspectives on Curriculum. Teachers College Record. 98 (6): 17-30.

Schwab, K. 2016. The Fourth Industrial Revolution. Geneva: World Economic Forum. 